\title{
1909 Taipei Earthquake Ground Motion Simulation
}

\author{
Yi-Wun Liao ${ }^{1}$, Yin-Tung Yen ${ }^{2}$, Shiann-Jong Lee ${ }^{3}$, and Kuo-Fong $\mathrm{Ma}^{1, *}$ \\ ${ }^{1}$ Department of Earth Sciences, National Central University, Taoyuan City, Taiwan, R.O.C. \\ ${ }^{2}$ Sinotech Engineering Consultant, Inc, Taipei, Taiwan, R.O.C. \\ ${ }^{3}$ Institute of Earth Sciences, Academia Sinica, Taipei, Taiwan, R.O.C.
}

Received 4 September 2015, revised 26 February 2016, accepted 2 March 2016

\begin{abstract}
The 1909 Taipei earthquake (M 7.3) occurred beneath the Taipei metropolitan area (TMA) causing substantial damage according to the historical literature. According to the hypocenter relocation and tectonic implications provided in a previous study, we simulated ground motions within the TMA using a hybrid simulation method involving the spectral-element method (SEM) and the empirical Green's function method (EGFM). We used the SEM for simulating low-frequency components and the EGFM for simulating high-frequency components. These high and low frequency components were subsequently combined. For the EGFM we used the records from a recent $\mathrm{M}_{\mathrm{L}} 4.9$ earthquake (11 October 2013, depth $=143.8 \mathrm{~km}$ ) in the Taipei area as the empirical Green's function. According to the historical literature, the observed PGA (peak ground acceleration) values are 59.2 and $67.0 \mathrm{gal}$ at ancient stations TAP and KEE, with periods of 1.21 and $1.34 \mathrm{~s}$, respectively. By comparing the simulated PGA values at modern stations TAPB and WFSB to the historical documented ones for 12 different models, our result suggests that the 1909 Taipei earthquake was an event with a magnitude of about $\mathrm{M}_{\mathrm{w}} 7.3$ and stress drop of approximately 30 bars, or a smaller equivalent magnitude between $\mathrm{M}_{\mathrm{w}} 6.8-7.3$ but with much higher average stress drop of more than 100 bars. For a deep event beneath TMA a larger vertical P-wave motion and longer period shaking wave, as addressed in the historical literature, might be expected with prolonged shaking as found in the simulation. A seismic hazard assessment is necessary for metropolitan Taipei to better understand the long period shaking from deep subduction zone intra plate events.
\end{abstract}

Key words: 1909 Taipei earthquake, Spectral element method, Empirical Green's function method, Hybrid simulation

Citation: Liao, Y. W., Y. T. Yen, S. J. Lee, and K. F. Ma, 2016: 1909 Taipei earthquake ground motion simulation. Terr. Atmos. Ocean. Sci., 27, 415-430, doi: 10.3319/TAO.2016.03.02.01(TEM)

\section{INTRODUCTION}

At 3:54 a.m. on 15 April 1909 an earthquake with a magnitude of 7.3 and depth of $80 \mathrm{~km}$ (Gutenberg and Richter 1954) occurred beneath the Taipei metropolitan area (TMA). This earthquake is often called the "1909 Taipei earthquake". Kanamori et al. (2012) used the global P-wave arrival times and S-P times recorded during the 1909 Taipei earthquake and relocated the epicenter at the northern end of Taiwan $\left(23.28^{\circ} \mathrm{N}, 121.52^{\circ} \mathrm{E}\right)$ to a hypocentral depth of $75 \mathrm{~km}$ (Fig. 1). According to the relocated hypocentral depth, Kanamori et al. (2012) defined the 1909 Taipei earthquake as an intra-slab event with earthquake magnitude $\mathrm{M}_{\mathrm{w}} 7.0 \pm 0.3$.

The earthquake caused 9 deaths and 51 injuries in addition to destroying 122 houses, partially destroying 252

\footnotetext{
* Corresponding author

E-mail:kuofongm@gmail.com
}

houses and damaging 798 houses (Taihoku Meteorological Observatory; TMO 1936, p. 149). Although this earthquake hazard was not as severe as some destructive historical earthquakes, Taipei is now much more populated than it was in 1909. Emphasis should therefore be placed on investigating possible seismic hazards similar to that from the 1909 Taipei earthquake, especially for future studies on long-period shaking effects on high-rise buildings. As shown in Fig. 1a, showing the seismicity from 1991 - 2013, no earthquake with magnitude greater than $M_{L} 6.0$ has occurred near the 1909 Taipei earthquake source area yet. It is, thus, difficult to clearly depict the ground motion behavior, such as peak ground acceleration (PGA), spectral accelerations (SA), and strong ground shaking duration associated with earthquakes that magnitude is as large as the 1909 event. We adopted a hybrid method involving the spectral-element method (SEM) and empirical Green's function method (EGFM) for 
simulating low- and high-frequency components to simulate the full ground motion spectra. For the EGFM simulation we used records from a deep earthquake event located under the TMA as the empirical Green's function (EGF) for the 1909 Taipei earthquake. We obtained the possible ground motion distribution from the 1909 Taipei earthquake using the hybrid simulation method. The possible earthquake source parameters such as magnitude and stress drop were defined by comparing the simulated ground motion values with the observed ground motion values recorded at two ancient stations, KEE and TAP, shown in Fig. 2, in the historical literature (TMO 1936, p. 149). The results can facilitate understanding the possible future seismic hazards in the Taipei basin from earthquakes similar to the 1909 Taipei earthquake.

\section{METHODS}

\subsection{Spectral Element Method (Frequency $<0.5 \mathrm{~Hz}$ )}

The SEM was first used for simulating fluid dynamics more than 20 years ago. Komatitsch and Vilotte (1998) and Komatitsch and Tromp (1999) introduced SEM application
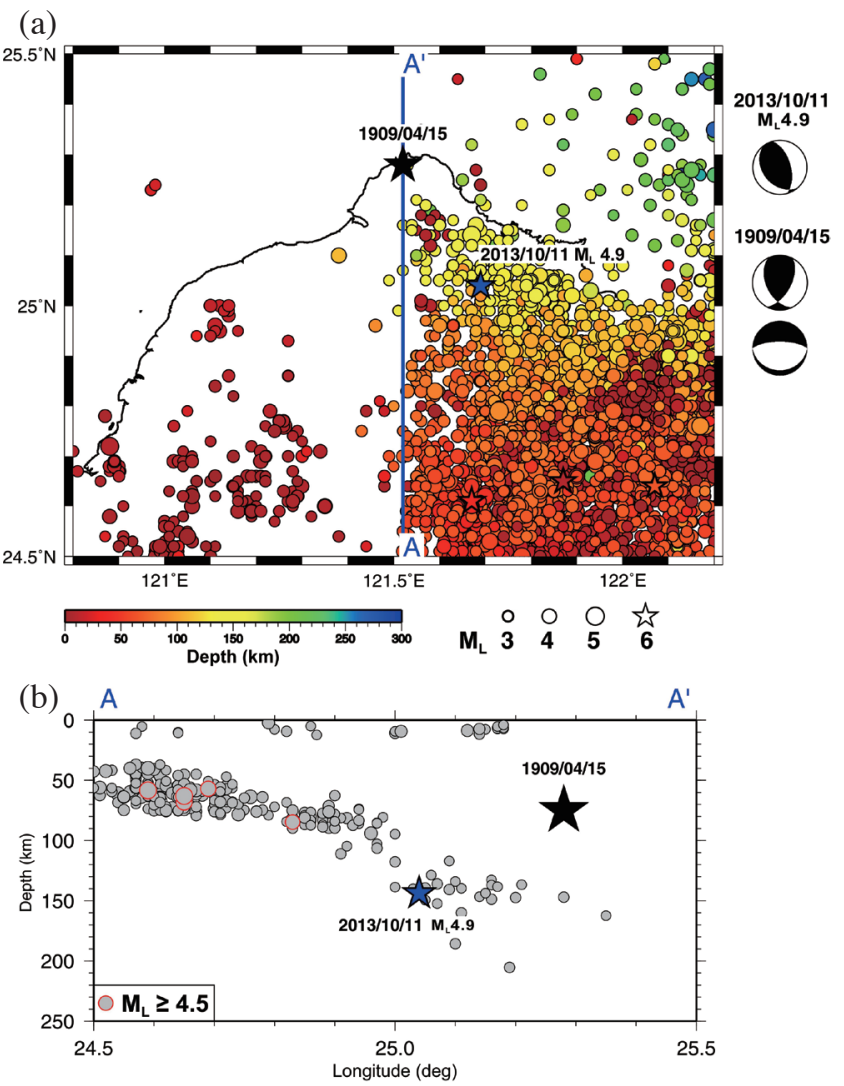

Fig. 1. (a) Seismicity of the TMA from 1991 - 2013. Black and blue stars represent the epicenters of the 1909 Taipei earthquake relocated by Kanamori et al. (2012) and the empirical Green's function (small event) used in the current study. (b) Cross-section of line AA'. Red circles represent earthquakes with magnitudes greater than $M_{L}$ 4.5. The focal mechanisms of the 1909 Taipei earthquake and the small event are shown beside the map. (Color online only) to 3D seismic-wave propagation. SEM requires the construction of an appropriate mesh for subsurface velocity structures and surface topography. Lee et al. (2008) constructed a mesh for Northern Taiwan and effectively simulated the 3D seismic-wave propagation characteristics in the Taipei basin. In addition to subsurface velocity structures derived by $\mathrm{Wu}$ et al. (2007) and a 40-m-resolution surface topography model, Lee et al. (2008) also considered the shallow subsurface structures of the Taipei basin derived from Wang et al. (2004) when constructing the mesh. In our study this adequately constructed mesh is used to compute the low-frequency components (frequency $<0.5 \mathrm{~Hz}$ ) of the broadband waveforms.

For broadband ground motion simulation the high frequency component simulation requires small earthquake selection as an EGF. The EGF selection details will be addressed in section 2.2. An east-dipping thrust fault which was determined from the focal mechanism of selected small earthquake (Fig. 1) was used for the SEM simulations. This focal mechanism was obtained using the Real-Time Moment Tensor Monitoring System (RMT, http://rmt.earth. sinica.edu.tw/; Lee et al. 2014). The RMT is an earthquake

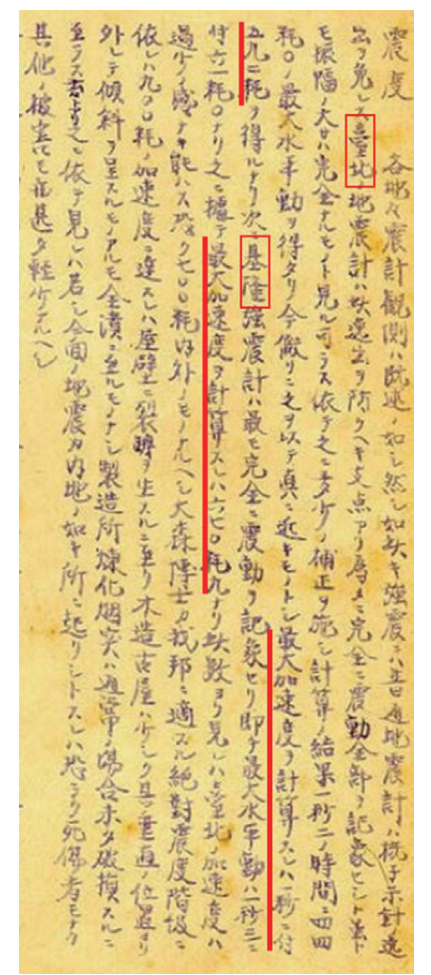

Fig. 2. Excerpt from the 1909 Taipei earthquake report from TMO (1936). This excerpt contains ground motion values for the two stations in the TMA: TAP and KEE. In the literature, the character "粍" was an unit used to quantify the ground motion values and is equal to $\mathrm{mm} \mathrm{s}^{-2}$. (Color online only) 
monitoring system using real-time broadband waveform data from Broadband Array in Taiwan for Seismology (BATS) and 3D Green's function database for the whole of Taiwan to automatically determine earthquake source parameters, including event origin time, hypocentral location, moment magnitude, and focal mechanism. The focal mechanism was double-checked using the first motion solution (using FPFIT, Reasenberg and Oppenheimer 1999). The east-dipping fault is also similar to one of the nodal planes from the subductiontype focal mechanism suggested by Kanamori et al. (2012).

We attempted to simulate two possible magnitudes for the 1909 Taipei earthquake: $\mathrm{M}_{\mathrm{w}} 6.8$ and 7.3, considered as the lower and upper boundaries for this event. Based on the scaling law between the moment and fault areas provided by Yen and Ma (2011), we created two finite faults corresponding to $\mathrm{M}_{\mathrm{w}} 6.8$ and 7.3 with effective areas of 200 and $900 \mathrm{~km}^{2}$, respectively.

An earlier study by Yen and Ma (2011) suggested that earthquakes with higher stress drops would yield higher PGA values in the near fault region as the hypocentral distance is about less than $30 \mathrm{~km}$. Considering that the 1909 Taipei earthquake was located deeply beneath the Taipei basin (focal depth $=75 \mathrm{~km}$, Kanamori et al. 2012), the slip distribution variation on the fault planes may not considerably influence the resulting waveforms received by stations at the surface. Therefore, average slip rates were applied homogeneously to the two fault planes, which were divided into subfaults with sizes of $1 \times 1 \mathrm{~km}^{2}$. We also assessed two epicenters, namely the location of the 1909 Taipei earthquake and the location of the selected small event, in this study. However, to examine the possible influence in the slip distribution heterogeneity on the fault to the ground motion at surface, we considered an additional case as an asperity model, having an asperity with 1.5 times the average slip and $20 \%$ of the fault area (Lee et al. 2016) in the upper portion of the fault. We, thus, compare the difference from this model to others as a reference in section 4.2.

\subsection{EGFM (Frequency $>0.5 \mathrm{~Hz})$}

The EGFM is used for computing the waveforms of an assumed large event by summing the waveforms from a small event near the source area of the large event (Irikura 1986). In the EGFM, instead of calculating Green's function by solving wave equations using a $3 \mathrm{D}$ velocity model, the waveforms of a small event are used as the EGFs for a large event. Therefore, we used a recent earthquake (11 October $2013 \mathrm{M}_{\mathrm{L}} 4.9$, depth: $143.8 \mathrm{~km}$ ) as the EGF for the 1909 Taipei earthquake (Fig. 1). As shown in Fig. 1b, although the small event was not located near the 1909 Taipei earthquake source area, with the lack of seismicity over two decades it was the most ideal choice in the 1909 Taipei earthquake focal area and it was the only event with a magnitude greater than $\mathrm{M}_{\mathrm{L}} 4.5$ with explicit records from the Central Weather
Bureau (CWB) and BATS. To compensate for the additional attenuation due to the difference in depths between the small event and the 1909 Taipei earthquake, we performed the hypocentral distance correction to modify the geometric spreading term. However, the effects of the inelastic attenuation were ignored in the simulation. After the hypocentral distance correction, the records from the small event were modified into waveforms for the target magnitudes. Thus, a two-step procedure was applied for simulating the highfrequency components:

\section{Step 1. Adjustment of hypocentral distances}

We first adjusted the amplitudes of the waveforms recorded by the stations illustrated in Fig. 3 using the hypocentral distance ratio for the small event to those for the 1909 Taipei earthquake for each station. The correction equation is expressed as follows:

$A m p_{\text {corr }}=A m p \times \frac{r_{\text {small }}}{r_{1909}}$

where, $A m p_{\text {corr }}$ and $A m p$ are the corrected amplitude and original amplitude, respectively, and $r_{\text {small }}$ and $r_{1909}$ are the hypocentral distances for the small event and the 1909 Taipei earthquake at each station, respectively. The computing time series are windowed as $2 \mathrm{~s}$ before to $50 \mathrm{~s}$ after the $S$-wave arrival. We did not compute the full waveforms

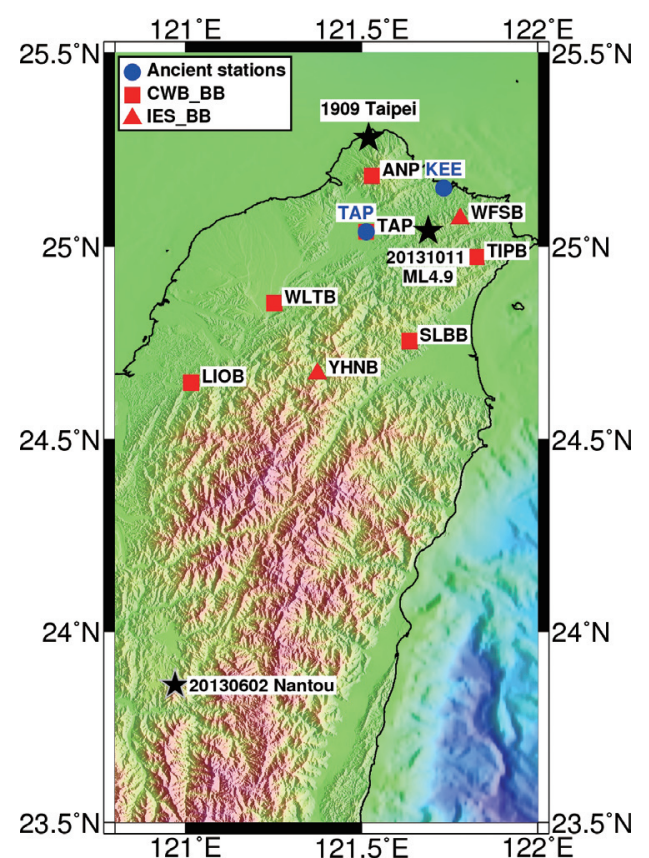

Fig. 3. Stations that recorded the small event (red symbols). Blue solid circles represent the historical stations. Black stars are the epicenters we assumed in the simulation: one is the epicenter of the small event, and the other is the epicenter of the 1909 Taipei earthquake relocated according to Kanamori et al. (2012). The epicenter of the 2013 Nantou earthquake is also shown in the map with a black star. (Color online only) 
because most of the peak ground motions occurred after $S$-wave arrival. However, for event right beneath TMA, although the peak motion is from waves arriving after the after $S$-wave, strong vertical P-wave motion within TMA might be expected compared to events from other region.

\section{Step 2. Modification to target magnitudes}

The adjusted waveforms were computed according to the equation provided by Miyake et al. (2003):

$U(t)=\sum_{i=1}^{N} \sum_{j=1}^{N} \frac{r}{r_{i j}} F(t) \times[C \cdot u(t)]$

where $U(t)$ and $u(t)$ represent the time series of the large event (1909 Taipei earthquake) and small event, respectively, at each station. $N$ and $C$ represent the scaling relation of the fault parameters and the stress drop ratio between the large event (1909 Taipei earthquake) and small event, respectively. $r$ and $r_{i j}$ represent the hypocentral distances for the small event and distances from the $i j$ th subfault to the stations, respectively. $F(t)$ is a filtering function for adjusting the difference in the source time functions between the large event (the 1909 Taipei earthquake) and small event.

\subsection{Model Construction for Hybrid Simulation}

According to the scaling law of fault parameters (Kanamori and Anderson 1975) and Omega square spectra (Aki 1967), $N$ and $C$ can be derived using the following equations:

$$
\frac{U(t)}{u(t)}=\frac{M_{0}}{m_{0}}=C N^{3}
$$

$\frac{A_{0}}{a_{0}}=C N$

where $M_{0}$ and $m_{0}$ are the seismic moments of the large and small events, respectively, and $A_{0}$ and $a_{0}$ are the acceleration spectra flat levels for the large and small events, respectively.

We assigned two values to $C$, namely 1 and 3.3, depending on specific considerations. According to Kanamori and Anderson (1975), the inter-plate and intra-plate earthquakes have stress drops of about 30 and 100 bars for most earthquakes, respectively. We thus considered these two values as the reference values for the 1909 earthquake simulation. It is possible that some intra-plate earthquakes might have stress drops lying between 30 and 100 bars, or larger, however, in this study we focus on using the general values, 30 and 100 bars, to give a reference for the 1909 Taipei earthquake simulation. We set $C$ to 1 when we considered that the 1909 Taipei earthquake had the same stress drop (30 bars) as that of the small event. We set $C$ to 3.3 when we considered that the 1909 Taipei earthquake was an intra-slab event with a stress drop of 100 bars. For the $N$ values the magnitudes of the small event were $\mathrm{M}_{\mathrm{L}} 4.9$ (from the CWB) and $\mathrm{M}_{\mathrm{w}} 4.2$ (from RMT), and our target magnitudes for the 1909 Taipei earthquake were $\mathrm{M}_{\mathrm{w}} 6.8$ and 7.3. We derived six $N$ values according to the aforementioned $C$ values (Table 1). After the epicenters were placed at the 1909 Taipei earthquake and small event locations, we derived a total of 12 models when simulating the high-frequency components.

According to the parameters listed in Table 1, six models are set, respectively, for the case that the epicenter is located at the location of the small event, and the determined location of the 1909 Taipei earthquake (Kanamori et al. 2012). In total, 12 models were tested in the simulation.

\section{Epicenter at the location of the small event:}

Model 1: Modifying the magnitude from $\mathrm{M}_{\mathrm{L}} 4.9$ to $\mathrm{M}_{\mathrm{w}} 6.8$.

Model 2: Modifying the magnitude from $\mathrm{M}_{\mathrm{w}} 4.2$ to $\mathrm{M}_{\mathrm{w}} 6.8$ with a 30-bar stress drop.

Model 3: Modifying the magnitude from $M_{w} 4.2$ to $M_{w} 6.8$ with a 100-bar stress drop.

Model 4: Modifying the magnitude from $\mathrm{M}_{\mathrm{L}} 4.9$ to $\mathrm{M}_{\mathrm{w}}$ 7.3.

Model 5: Modifying the magnitude from $\mathrm{M}_{\mathrm{w}} 4.2$ to $\mathrm{M}_{\mathrm{w}} 7.3$ with a 30-bar stress drop.

Model 6: Modifying the magnitude from $\mathrm{M}_{\mathrm{w}} 4.2$ to $\mathrm{M}_{\mathrm{w}} 7.3$ with a 100-bar stress drop.

Epicenter at the location of the 1909 Taipei earthquake: Model 7: Modifying the magnitude from $\mathrm{M}_{\mathrm{L}} 4.9$ to $\mathrm{M}_{\mathrm{w}} 6.8$.

Model 8: Modifying the magnitude from $\mathrm{M}_{\mathrm{w}} 4.2$ to $\mathrm{M}_{\mathrm{w}} 6.8$ with a 30-bar stress drop.

Model 9: Modifying the magnitude from $\mathrm{M}_{\mathrm{w}} 4.2$ to $\mathrm{M}_{\mathrm{w}} 6.8$ with a 100-bar stress drop.

Model 10: Modifying the magnitude from $M_{L} 4.9$ to $M_{w}$ 7.3.

Model 11: Modifying the magnitude from $\mathrm{M}_{\mathrm{w}} 4.2$ to $\mathrm{M}_{\mathrm{w}} 7.3$ with a 30-bar stress drop.

Model 12: Modifying the magnitude from $\mathrm{M}_{\mathrm{w}} 4.2$ to $\mathrm{M}_{\mathrm{w}} 7.3$ with a 100-bar stress drop.

\subsection{Hybrid Method}

We summed the filtered time series for the high- and low-frequency components to obtain waveforms with broadband frequencies. Figure 4 illustrates two examples to show the unfiltered spectra of Model 2 at stations ANPB and TAPB (Fig. 2). In the plots for both stations, the low-frequency component and high-frequency component spectra matched adequately at frequencies ranging from $0.5-0.8 \mathrm{~Hz}$. However, the low-frequency component spectra suddenly increased at $0.8 \mathrm{~Hz}$ at station TAPB because of numerical dispersions in the low-frequency components simulation. We, thus, filtered the low-frequency components to frequencies lower than $0.5 \mathrm{~Hz}$ and the high-frequency components to frequencies higher than $0.5 \mathrm{~Hz}$ for all stations to prevent this numerical dispersion. The matching frequency point might be higher than the corner frequencies for magnitude $\mathrm{M}_{\mathrm{w}} 7$ earthquakes, 
Table 1. Parameters used in the EGFM.

\begin{tabular}{|c|c|c|c|}
\hline Mag. of EGF & $\mathrm{M}_{\mathrm{L}}=4.9(\mathrm{CWB})$ & $\mathrm{M}_{\mathrm{w}}=4.2(\mathrm{RMT})$ & $\mathrm{M}_{\mathrm{w}}=4.2(\mathrm{RMT})$ \\
\hline$m_{0}($ dyne-cm) & $2.84 \times 10^{23}($ Chen et al. 2007) & $2.5 \times 10^{22}($ Kanamori 1977$)$ & $2.5 \times 10^{22}$ (Kanamori 1977) \\
\hline \multicolumn{4}{|c|}{ Target magnitude $M_{w} 6.8$} \\
\hline$M_{0}($ dyne-cm) & \multicolumn{3}{|c|}{$1.995 \times 10^{26}($ Kanamori 1977$)$} \\
\hline$N$ & 9 & 20 & 14 \\
\hline$C$ & 1 & 1 & 3.3 \\
\hline Subfault size & $2.22 \times 1.11 \mathrm{~km}$ & $1 \times 0.5 \mathrm{~km}$ & $1.43 \times 0.71 \mathrm{~km}$ \\
\hline Rise time of small event & $0.13 \mathrm{~s}$ & $0.06 \mathrm{~s}$ & $0.085 \mathrm{~s}$ \\
\hline \multicolumn{4}{|c|}{ Target magnitude $M_{w} 7.3$} \\
\hline$M_{0}($ dyne-cm) & \multicolumn{3}{|c|}{$1.11 \times 10^{27}($ Kanamori 1977$)$} \\
\hline$N$ & 16 & 35 & 25 \\
\hline$C$ & 1 & 1 & 3.3 \\
\hline Subfault size & $1.88 \times 1.88 \mathrm{~km}$ & $0.86 \times 0.86 \mathrm{~km}$ & $1.2 \times 1.2 \mathrm{~km}$ \\
\hline Rise time of small event & $0.13 \mathrm{~s}$ & $0.06 \mathrm{~s}$ & $0.085 \mathrm{~s}$ \\
\hline
\end{tabular}

(a)
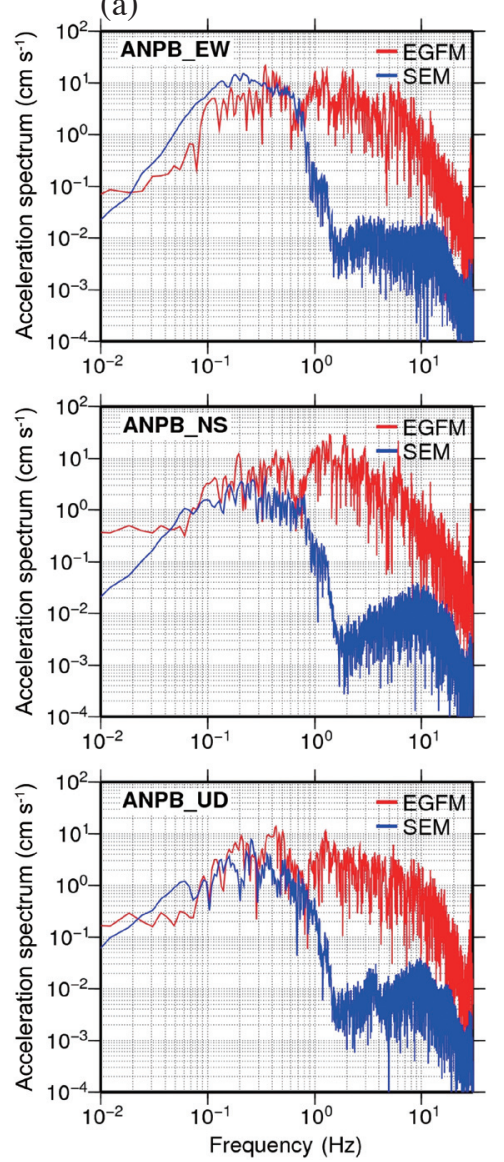

(b)
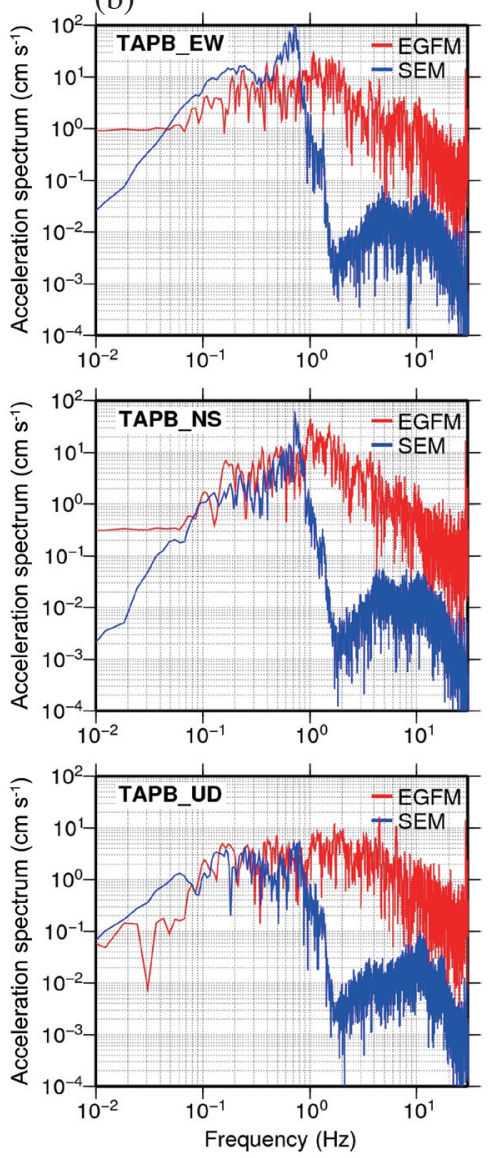

Fig. 4. Unfiltered spectra of Model 2. (a) Spectra of station ANPB, and (b) spectra of station TAPB. Blue lines represent the low-frequency components computed using the SEM, and red lines represent the high-frequency components obtained using the EGFM. (Color online only) 
however, the source time function for the small event was adjusted into the source time function for the large event using a filtering function $F(t)$ when simulating the high-frequency components using the EGFM. The source time functions in the low-frequency simulations using SEM corresponded to the magnitudes of the events. Thus, the source time functions in hybrid simulation would still be adequate for the corresponding magnitudes.

\section{RESULTS}

\subsection{More Reasonable Magnitude of the Small Event}

Figure 5 shows the synthetic waveforms for Models 1 and 2 obtained using the hybrid simulation method. The PGA values for Model 1 ranged from 2.80 - 15.94 gal, with most of the PGA values lower than 10 gal. The PGA values for Model 2 ranged from 6.35 - $47.95 \mathrm{gal}$. According to the PGA values, when we assumed that the magnitude of the small event was $M_{L} 4.9$, the ground motion values for the simulated waveforms were lower than those derived from $M_{w}$ 4.2. Figure 6 illustrates the filtered spectra and combined spectra of Models 1 and 2. The spectra of the low- and highfrequency components for Model 1 demonstrated an obvious gap at $0.5 \mathrm{~Hz}$ (Fig. 6a). However, the spectra for Mod- el 2 demonstrated an adequate match at $0.5 \mathrm{~Hz}$ (Fig. 6b). The spectra of the high-frequency components for Model 1 seemed to be underestimated. We adopted the SAs from the $2013 \mathrm{M}_{\mathrm{w}} 6.2$ Nantou earthquake as a reference to justify whether the ground motion intensities of the synthetic waveforms were reasonable. Consider, for example, station TAPB (Fig. 7); the acceleration responses at each frequency component of Model 1 were considerably lower than those of Models 2 and 3, particularly in the north-south component. The SA values scale was approximately $0.01 \mathrm{~g}$ for Model 1 but $0.02 \mathrm{~g}$ for the Nantou earthquake. Specifically, the SA values from an $\mathrm{M}_{\mathrm{w}} 6.2$ event were almost twice as high as those from an $\mathrm{M}_{\mathrm{w}} 6.8$ event. Thus, modifying the magnitude of the small event from $\mathrm{M}_{\mathrm{L}} 4.9$ to the target magnitudes was unreasonable. Therefore, the models in which the magnitude was modified from $\mathrm{M}_{\mathrm{L}} 4.9$ (Models 1, 4, 7, and 10) are not further addressed in the following sections.

\subsection{Results with Different Stress Drop Values, Target Magnitudes, and Epicenters}

As mentioned in the previous section, we assumed two values for the stress drop: 30 and 100 bars. According to the synthetic waveforms illustrated in Figs. $5 \mathrm{~b}$ and $8 \mathrm{a}$, the
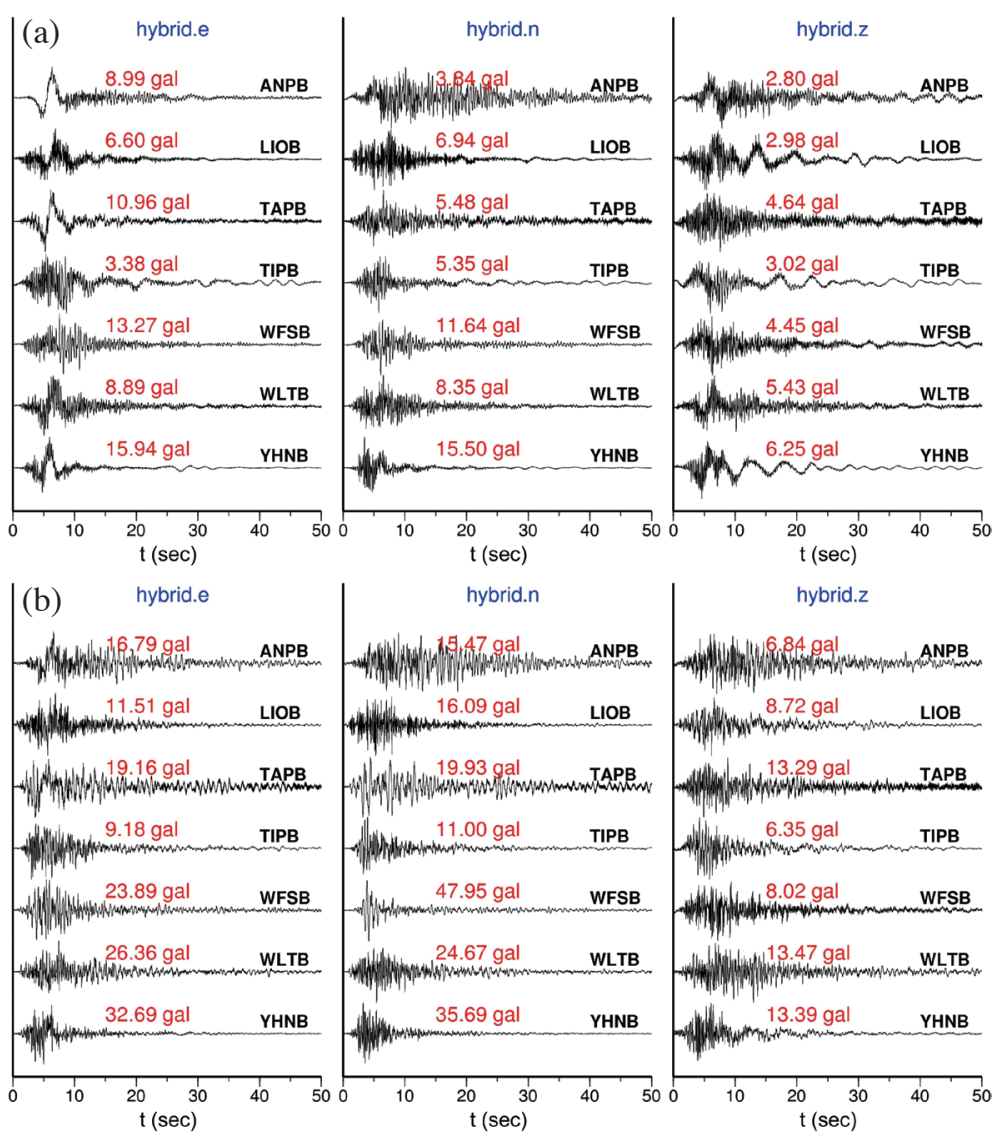

Fig. 5. Synthetic waveforms of (a) Model 1 and (b) Model 2 combined using the hybrid simulation method. All the waveforms were normalized by their peak amplitudes and started from 2 seconds before the $S$-wave arrivals. The peak amplitudes are marked beside the waveforms. (Color online only) 

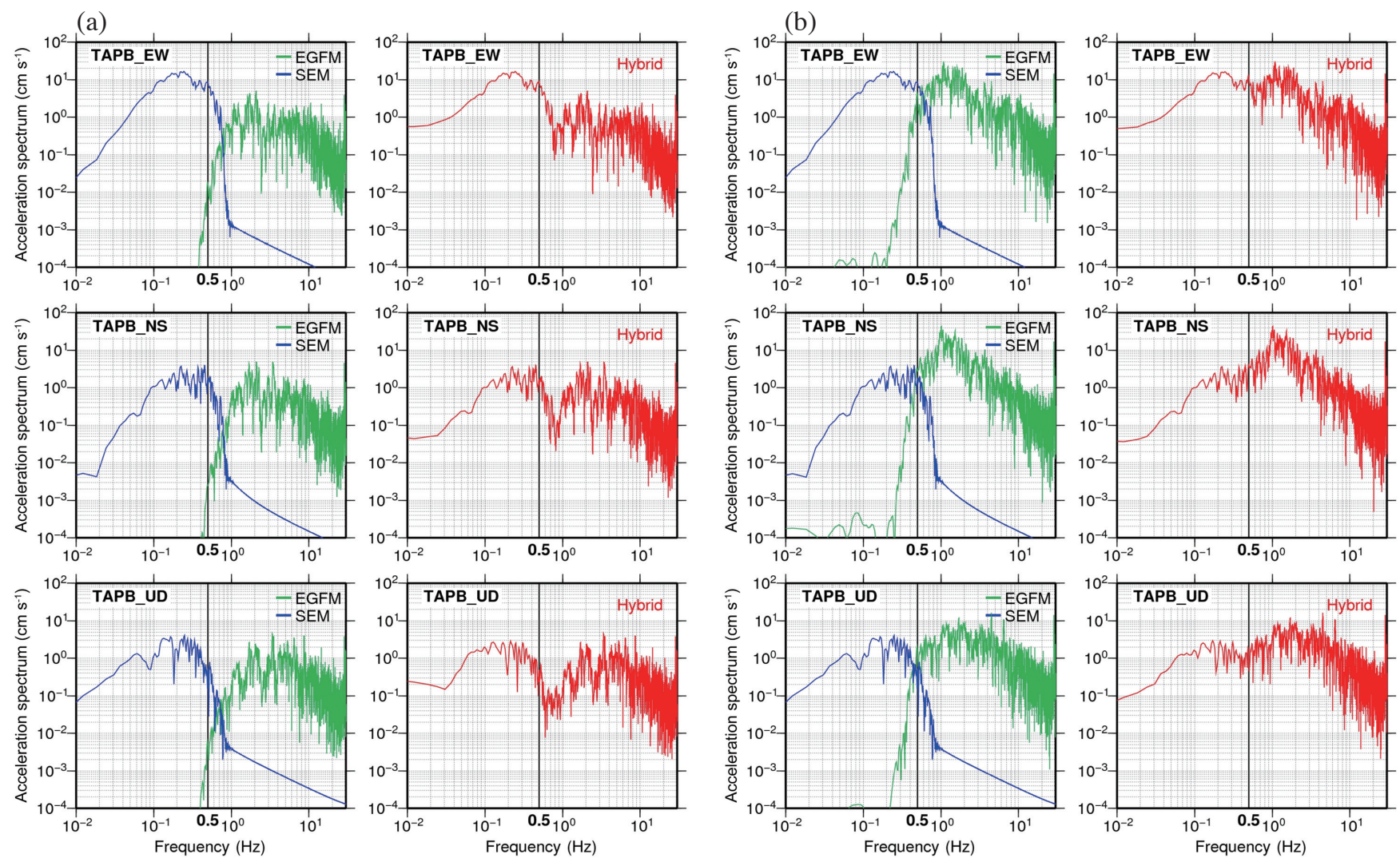

Fig. 6. Filtered synthetic spectra and combined synthetic spectra at station TAPB. (a) Synthetic spectra of Model 1 and (b) Model 2. Blue lines and green lines represent the synthetic spectra of the low- and high-frequency components simulated using the SEM and EGFM, respectively. The red lines are the combined synthetic spectra. (Color online only)

(a)

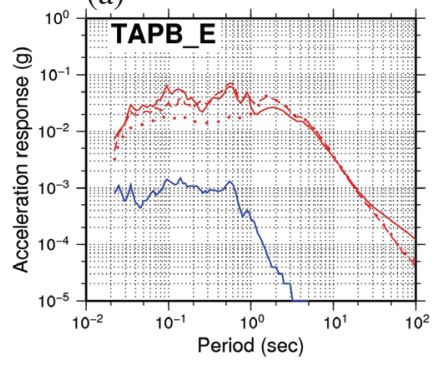

(b)

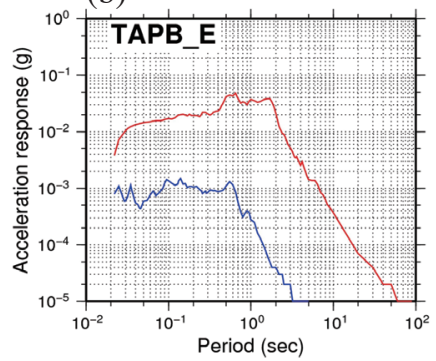

Spectral acceleration (Damping 5\%)
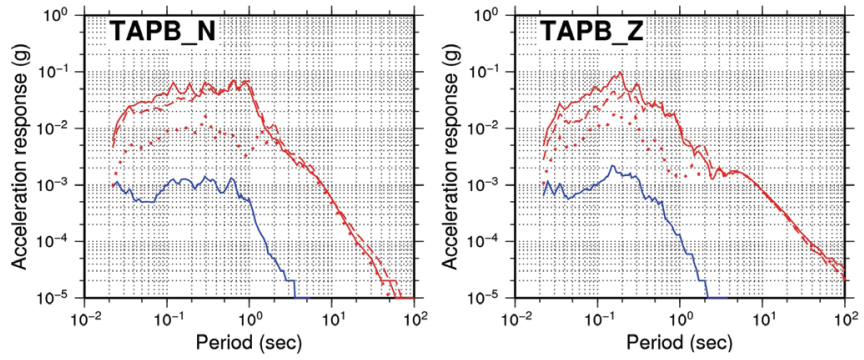

$M_{\mathrm{w}} 4.2 \rightarrow M_{\mathrm{w}} 6.8$ Stress drop $=100$ bars (Model 3)

$---M_{w} 4.2 \rightarrow M_{w} 6.8$ Stress drop $=30$ bars (Model 2)

.... $\mathrm{M}_{\mathrm{L}} 4.9 \rightarrow \mathrm{M}_{\mathrm{w}} 6.8$ (Model 1)

2013/10/11 Taipei $M_{w} 4.2$ (The small event)
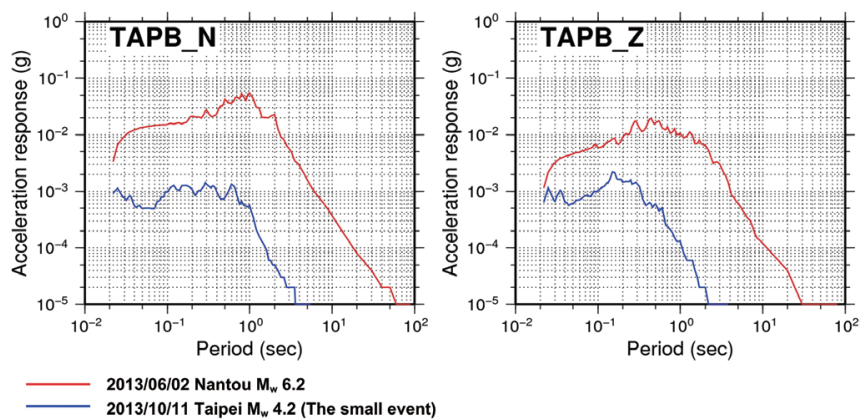

Fig. 7. SAs of the synthetic waveforms, 2013 Nantou earthquake and small event at station TAPB. (a) Red and blue SA curves were calculated from the synthetic waveforms (Models 1,2, and 3) and observed waveforms for the small event. (b) Red and blue SA curves were calculated from the observed waveforms of the 2013 Nantou earthquake and observed waveforms of the small event. (Color online only) 

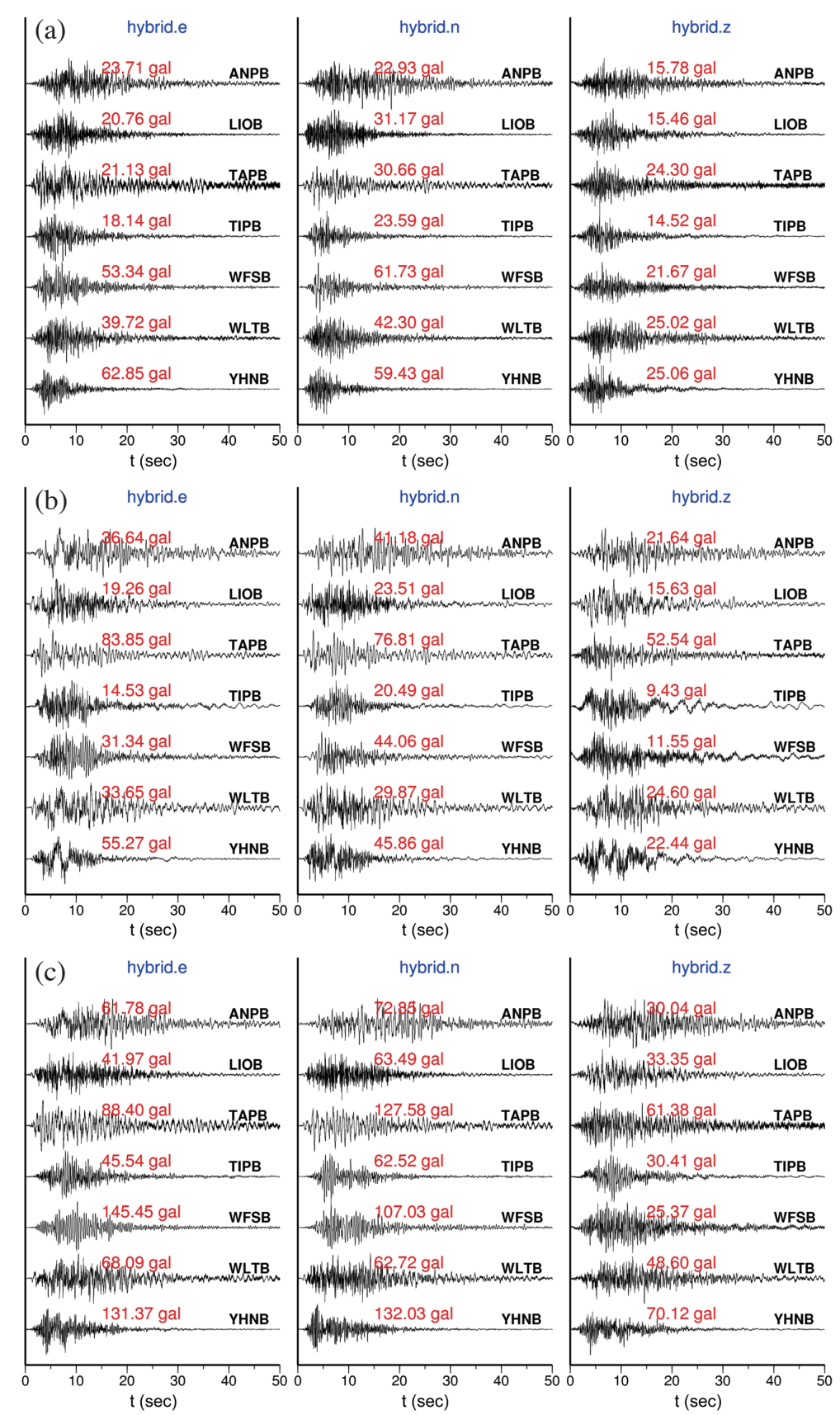

Fig. 8. Synthetic waveforms from (a) Model 3, (b) Model 5, and (c) Model 6 combined using the hybrid simulation method. All the waveforms were normalized by their peak amplitudes and started from $2 \mathrm{~s}$ before the $S$-wave arrivals. The peak amplitudes are marked beside the waveforms. (Color online only)

ground motion values obtained from the model with a 100bar stress drop (Model 3, Fig. 8a) were higher than those obtained from the model with a 30-bar stress drop (Model 2, Fig. 5b), even though both models reached the same target magnitude. The simulated ground motions derived from Model 3 demonstrated a similar scale to that of the ground motions derived from the model with a target magnitude of $\mathrm{M}_{\mathrm{w}} 7.3$ and stress drop of 30 bars (Model 5, Fig. 8b). All results from both target magnitudes (Figs. 5b and 8 ) revealed that the models with higher stress drop values would result in higher ground motion values.

According to the hypocentral depth relocated by Kanamori et al. (2012) and the location of the small earthquake event, we simulated the 1909 Taipei earthquake by having two epicenter assumptions. Figure 9 shows synthetic waveforms obtained from the models (Models 8 and 9) in which the epicenter was relocated according to Kanamori et al. (2012). Here, we present only the results from the models with a target magnitude of $\mathrm{M}_{\mathrm{w}}$ 6.8. No obvious differences were observed in the scale and distribution of ground 
motion values between the models with the epicenter located at the location of the small event and those with the epicenter relocated according to Kanamori et al. (2012). The ground motions distribution seemed to be dominated by the original ground motion behavior of the small event.

\section{DISCUSSION}

\subsection{Comparison of Simulated PGA Values with PGA Values Predicted Using the Ground-Motion Prediction Equation}

\subsubsection{Peak Ground Acceleration}

We compared the simulated PGA values from Models 2, 3, 5, and 6 with the PGA values predicted using the ground-motion prediction equation (GMPE) presented by Lin et al. (2012) (Fig. 10). Considering the site corrections for each station (Kuo et al. 2011,2012), all of the simulated PGA values were found to be lower than the PGA values predicted using the GMPE. In the simulations for high-frequency components using EGFM we ignored the inelastic attenuation effects, which might be one of the reasons why the simulated PGA values are smaller than those derived from GMPE. Furthermore, the PGA values used in the regressions for the GMPE were the geometric means of the east-western components and north-south components of PGA values, and most of the events adopted for the GMPE were located outside the Taipei area (e.g., the Ryukyu trench, longitudinal valley, and western foothills). However, since the hypocenter of the 1909 Taipei earthquake was deep beneath the Taipei basin, the contribution of the two horizontal components may be smaller than those from outside the Taipei basin. The vertical components of the 1909 Taipei earthquake might contain more energy than the earthquakes adopted for the GMPE. The PGA values comparison implied that rays originating from deep beneath the Taipei basin cause smaller ground shaking in horizontal components than rays traveling horizontally from outside of the Taipei area do. This might be a piece of good news in a way of PGA point of view for events beneath the Taipei basin. However, current derived GMPE does not consider P-wave, and the period of motion was not yet presented, it is possible that the events beneath Taipei might have stronger $\mathrm{P}$-wave and longer period waves compared to the events from outside of Taipei basin. This would require further examination to understand the impacts of vertical motion from P-wave and longer period shaking for events beneath and outside TMA.

\subsubsection{Spectral Acceleration (SA)}

We compared the simulated and predicted response spectra in addition to the PGA comparison (SA; Fig. 11). The simulated SA curves were similar to the predicted SA curves at most of the stations, particularly for the SA curves from the models with a 100-bar stress drop. The SA curves dropped near the 0.03 -s mark because the broadband instruments from BATS and the CWB do not cover a consistent frequency band at high frequencies. The upper limits of the recorded frequencies ranged from $30-50 \mathrm{~Hz}$. We filtered the waveforms to frequencies lower than $30 \mathrm{~Hz}$ to ensure that the waveforms contained the same frequency band range. The simulated SA curves demonstrated a closer match to the GMPE-predicted curves than the simulated PGA values did. This is because some of the high-frequency energy from the small event may have been attenuated during the longdistance the waves traveled from deep beneath the Taipei basin. The inelastic attenuation ignored in the simulations might have influences upon the ground motion values. In parts of the high-frequency components would also need to be taken into consideration.

\subsection{Heterogeneity of Slip Distribution to the Ground Motions at Surface}

For the fault plane slip distribution we assumed a homogeneous slip distribution on each fault plane in our simulations. However, for concern for the possible slip heterogeneity to the ground motion at surface, we made a heterogeneous slip distribution model with an asperity at the upper part of the fault plane, as shown in Fig. 12, for the magnitude 7.3 case. The hypocenter was at the relocated location from Kanamori et al. (2012), and the slip amount on the asperity was set as the 1.5 times the average slip, thus, for an average stress drop of 100 bars, the stress drop on the asperity and the other area would be 335 and 68 bars, respectively. As shown in Fig. 13, the PGA values from heterogeneous models are not significantly different from those from homogeneous models. We also compared the SA curves between the homogeneous and heterogeneous models in Fig. 14. The SA curves from the heterogeneous model almost overlaps the SA curves from the homogeneous model except for slight differences in $2-5 \mathrm{~s}$ periods. The slip heterogeneity effect on the ground motions at surface might not be that significant as we considered a deep $(\sim 75 \mathrm{~km})$ event.

\subsection{Comparison with Recorded Ground Motions in the Historical Literature}

Because there are no available waveforms from the ancient stations in Taiwan available for the historical 1909 event, we could not compare the waveforms derived in this study with historical waveforms. However, as illustrated in Fig. 2, the ground motion values recorded at the stations KEE (Keeling) and TAP (Taipei) were recorded in the historical literature (TMO 1936, p. 149). In the literature the unit “粍” is equal to $\mathrm{mm}$, and the PGA of stations KEE and TAP are 670 and 592 粍. These PGA values from the historical literature were converted from the recorded period, as mentioned to be around $1.2 \mathrm{~s}$ in the literature, and 

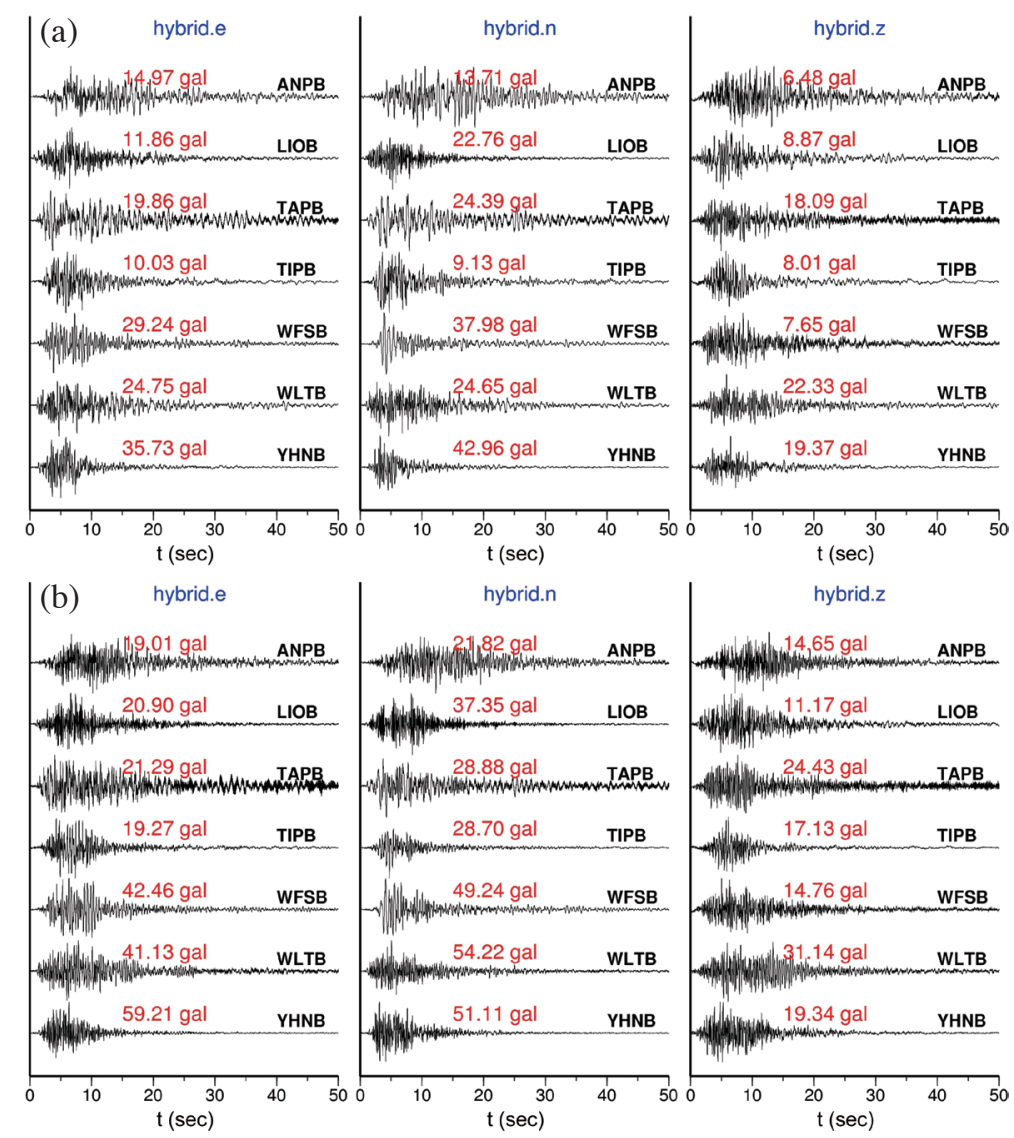

Fig. 9. Synthetic waveforms from (a) Model 8 and (b) Model 9 combined using the hybrid simulation method. All the waveforms were normalized by their peak amplitudes and started from $2 \mathrm{~s}$ before the $S$-wave arrivals. The peak amplitudes are marked beside the waveforms. (Color online only)
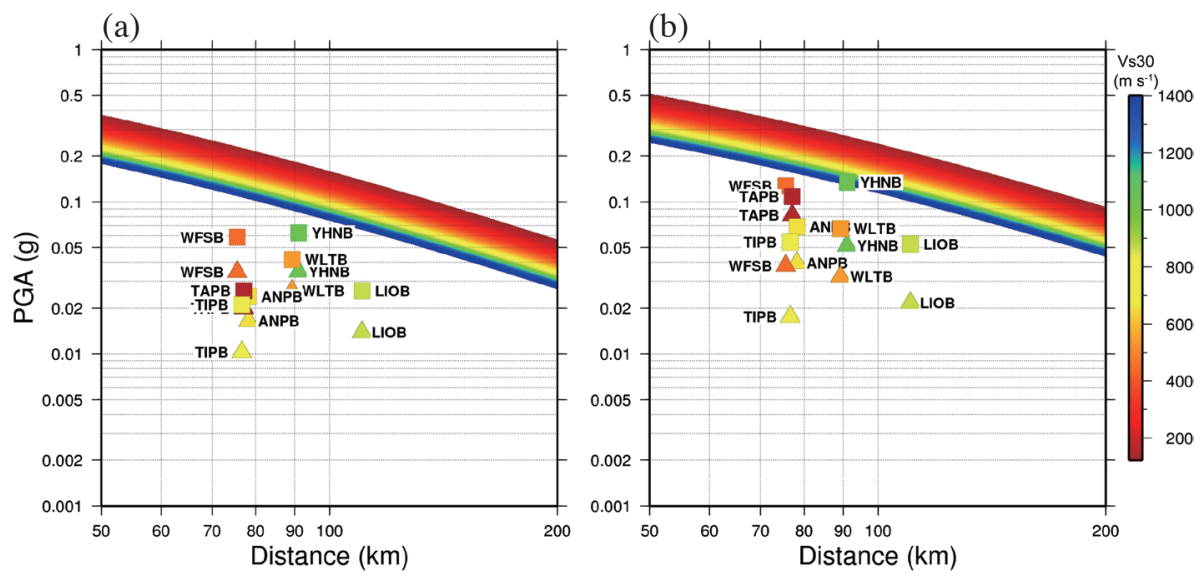

Fig. 10. Comparison of the PGA values simulated at each station with the PGA values predicted using the GMPE. (a) Comparison of Models 2 and 3 with the predicted PGA values, and (b) comparison of Models 5 and 6 with the predicted PGA values. Color bars represent the Vs30 values (Kuo et al. 2011, 2012) for each station. Squares and triangles represent the simulated PGA values from the two models with stress drops of 100 and 30 bars, respectively. This figure shows only the comparison of the models in which the epicenter was located at the location of the small event. (Color online only) 

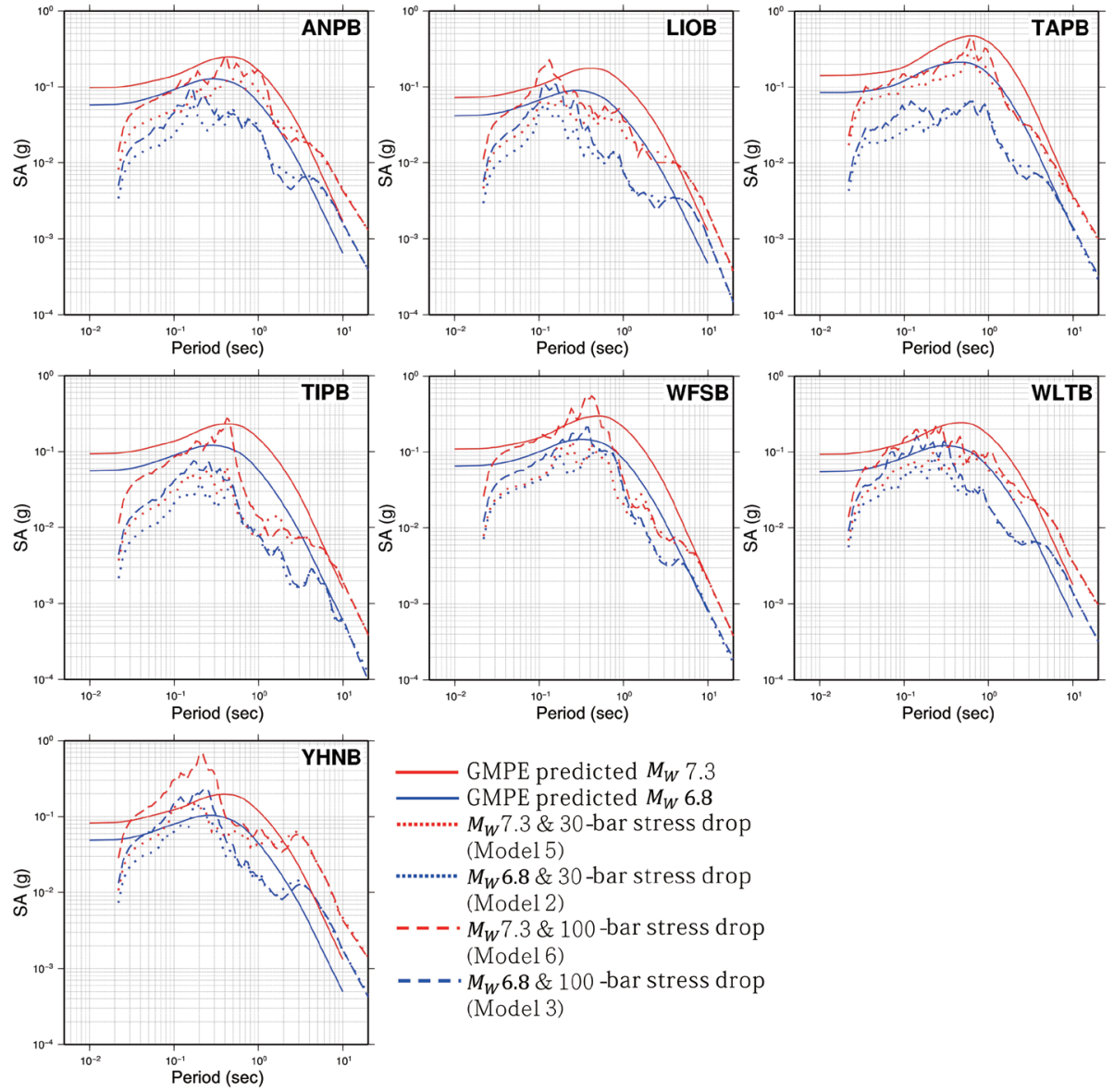

- GMPE predicted $M_{W} 7.3$

GMPE predicted $M_{W} 6.8$

$M_{W} 7.3 \& 30$-bar stress drop (Model 5)

........... $M_{W} 6.8 \& 30$-bar stress drop (Model 2)

$---\cdot M_{W} 7.3 \& 100$-bar stress drop

(Model 6)

$---\cdot M_{W} 6.8 \& 100$-bar stress drop

(Model 3)

Fig. 11. Comparison of the simulated SA from Models 2, 3, 5, and 6 with the SA predicted using the GMPE. Red lines represent models with a magnitude of 7.3, and blue lines represent models with a magnitude of 6.8. Solid lines indicate the GMPE predicted SA curves, dotted lines indicate the SA curves from the models with a 30-bar stress drop, and dashed lines indicate the SA curves from the models with a 100-bar stress drop. This figure shows only the comparison of the models in which the epicenter was located at the location of the small event. (Color online only)

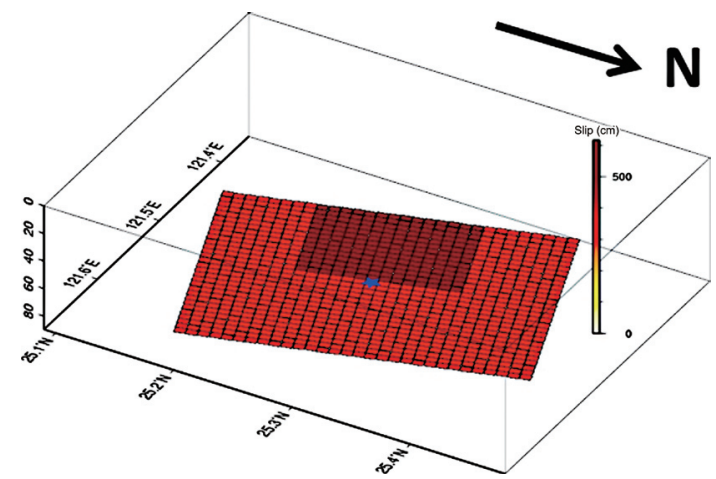

Fig. 12. Heterogeneous slip distribution model with an asperity located at the upper part of the fault plane. The black arrow indicates the direction of north, and the blue star is the location of hypocenter. (Color online only) 


\section{Homogeneous slip distribution}
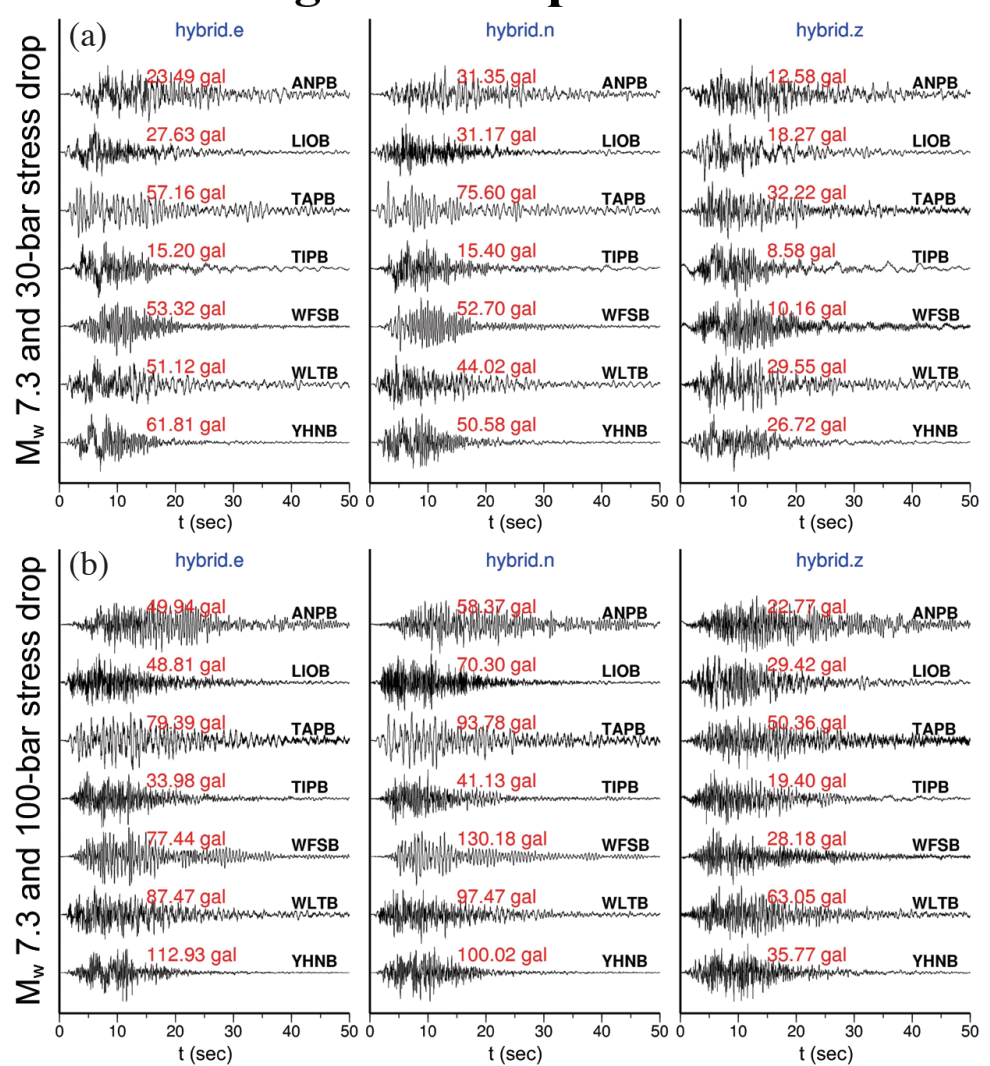

\section{Heterogeneous slip distribution}
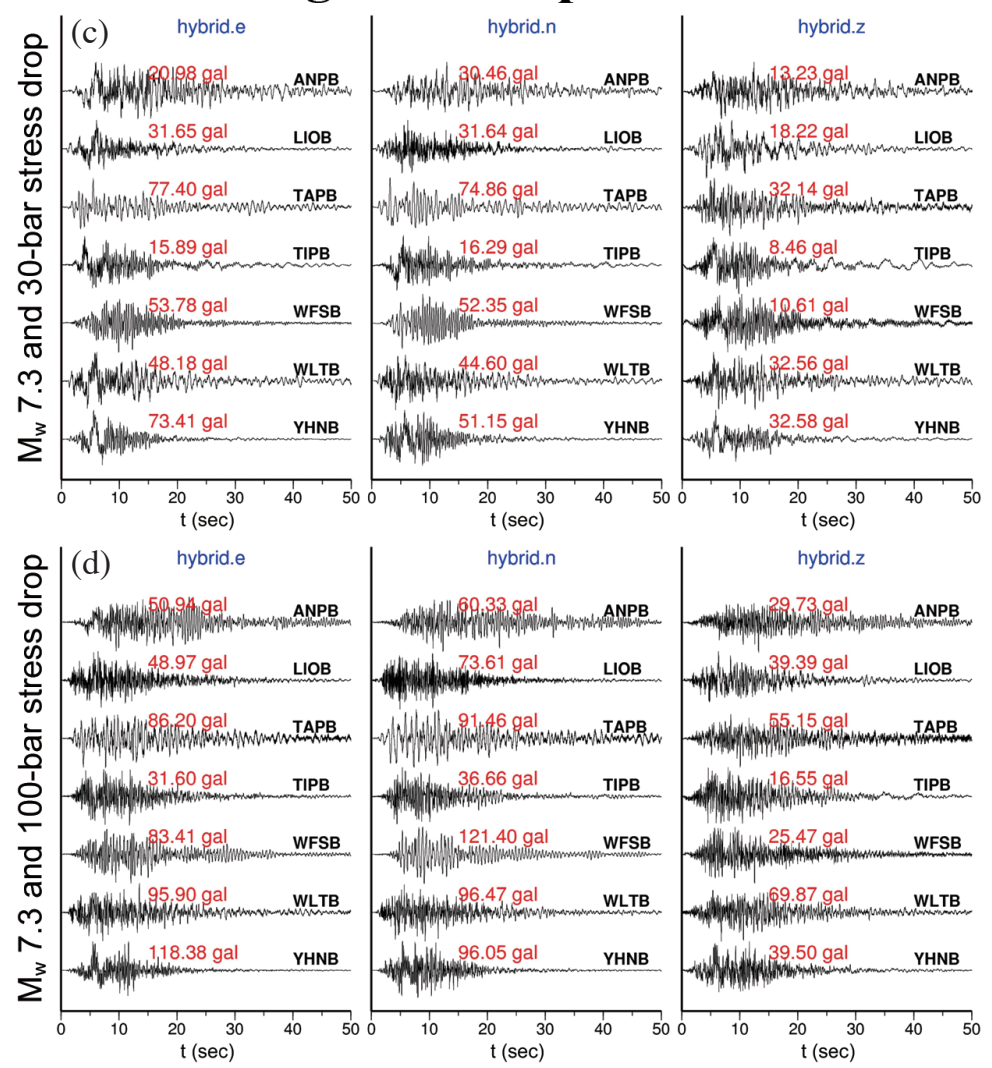

Fig. 13. Synthetic waveforms from the homogeneous (Models 11 and 12) and heterogeneous slip models. (a) and (b) are derived from the homogeneous slip model, while (c) and (d) are derived from the heterogeneous slip model. All the waveforms were normalized by their peak amplitudes and started from $2 \mathrm{~s}$ before the $S$-wave arrivals. The peak amplitudes are marked beside the waveforms. (Color online only) 

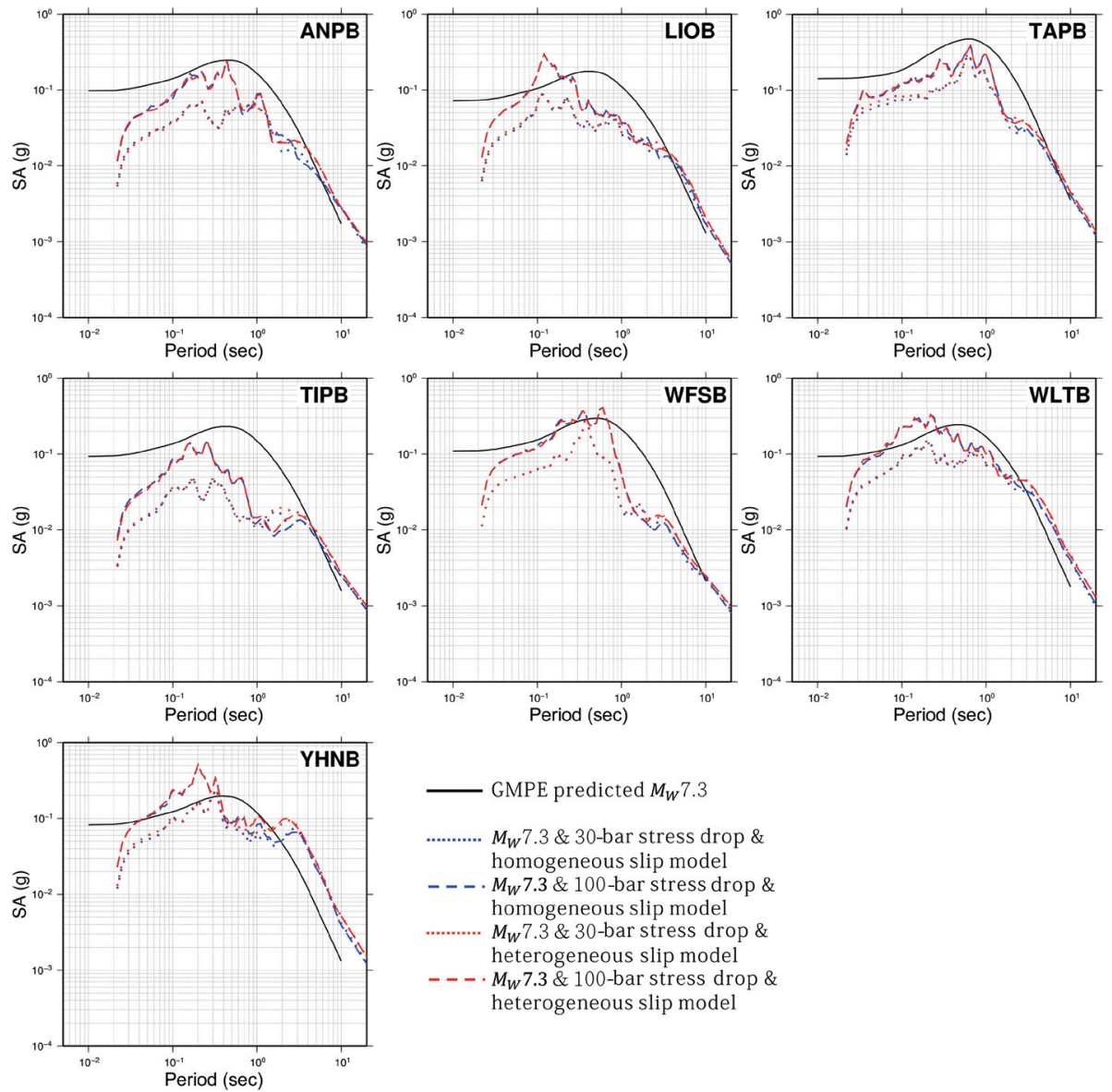

heterogeneous slip model

Fig. 14. Comparison of the SA curves of homogeneous and heterogeneous slip models. The red dashed and dotted lines represent the SA curves from the heterogeneous slip models with the same magnitude of $\mathrm{M}_{\mathrm{w}} 7.3$ and two different stress drop values of 30 and 100 bars, and the blue line represent those from homogeneous models. The black lines are the GMPE predicted SA curves for reference. (Color online only)

the displacement. The unit “粍” now could be considered as $\mathrm{mm} \mathrm{s}^{-2}$. By all means, the PGA values recorded by the Omori seismometer at KEE and TAP could be considered as 67.0 and 59.2 gal, respectively. Although the instrument response of the ancient instrument from Omori strong motion instrument was not corrected, we consider the PGA values as the direct comparison to our hybrid simulation. However, it is also worth that the characteristic period is about $1.2 \mathrm{~s}$ for these observations. It is possible that the literature stated PGA might be in the period of $1 \mathrm{~s}$, and our simulation is for PGA at higher frequency as higher than $1 \mathrm{~Hz}$. Table 2 lists the observed and synthetic PGA values from each model. Because the ancient station TAP and current station TAPB are identical in location, the synthetic PGA values of TAPB can be compared with those observed at TAP. As the ancient station KEE no longer exists, we consider the current close-by station WFSB (Wufeng Mountain) for the hybrid simulation and PGA comparison. The simulated PGA values for $\mathrm{M}_{\mathrm{w}} 7.3$ have similar scale with the observed values with deviation of mostly less than 30 gal, especially for the case of stress drop 30 bars, while those for $M_{w} 6.8$ are much larger in difference over 30 gal. This suggests that the mod- els with a target magnitude of $\mathrm{M}_{\mathrm{w}} 7.3$ with stress drop of 30 bars might be more compatible to the 1909 Taipei earthquake, as shown in Table 2. However, comparing the simulated PGA to the historical observation at station TAPB for different magnitude and stress drop, it is also possible that the 1909 earthquake was a magnitude $M_{w} 7.3$ with average stress drop of $30-100$ bars, or $\mathrm{M}_{\mathrm{w}}$ of $6.8-7.3$, but with much higher average stress drop of more than 100 bars.

\subsection{Ground Motion and Shaking Duration}

In addition to ground motion values, the duration of ground shaking has recently been assessed in earthquake hazard assessments. For estimating strong shaking duration, we adopted the definition of shaking durations from Lee et al. (2015), who evaluated the amplitudes of ground motions and incorporated the accumulated energy of waveforms to estimate the shaking duration. According to Lee et al. (2015), the ground shaking duration is defined as the lapsed time for energy content from 5 - 95\% in the interval between the first and last amplitudes greater than the threshold, here it's 10 gal. Figure 15 illustrates the plots of PGA value and 
strong shaking duration. Because the shaking duration is defined from the threshold, higher PGA values may correspond to longer strong shaking duration. However, stations ANPB and TAPB (the station in the Taipei basin) did not record the highest PGA values, but they recorded prolonged strong shaking duration. Assessments of whether buildings can resist longer strong ground shaking duration must be emphasized in future earthquake hazard assessments.

\section{CONCLUSIONS}

We simulated the 1909 Taipei earthquake using a hybrid simulation method that included the SEM for low- frequency components and the EGFM for high-frequency components. A recent small event that occurred deep beneath the Taipei basin was used as the EGF for the 1909 Taipei earthquake. We considered 12 models for the simulation by evaluating the magnitudes of the small event, target magnitudes, stress drop values, and possible epicenters. The results revealed that the small event exhibited a highly reasonable magnitude of $\mathrm{M}_{\mathrm{w}} 4.2$ and that no obvious differences existed between the ground motion behaviors derived from models with dissimilar epicenters. We used the ground motion values from the historical literature as a reference and observed that the simulated PGA values from models with a magnitude of $\mathrm{M}_{\mathrm{w}} 7.3$ and stress drop of 30 bars were

Table 2. Comparison of observed PGA values (from the historical literature) and synthetic PGA values from each model.

\begin{tabular}{ccc}
\hline \multicolumn{4}{c}{ 1909 literature record } \\
\hline & TAP/TAPB & KEE/WFSB \\
\hline Location of 20131011 & $59.2 \mathrm{gal}$ & $67.0 \mathrm{gal}$ \\
\hline Model 2: $\mathrm{M}_{\mathrm{w}} 6.8$ (Stress drop = 30 bars) & $19.5 \mathrm{gal}$ & $33.8 \mathrm{gal}$ \\
Model 3: $\mathrm{M}_{\mathrm{w}} 6.8$ (Stress drop = 100 bars) & $25.5 \mathrm{gal}$ & $57.4 \mathrm{gal}$ \\
Model 5: $\mathrm{M}_{\mathrm{w}} 7.3$ (Stress drop = 30 bars) & $80.2 \mathrm{gal}$ & $37.2 \mathrm{gal}$ \\
Model 6: $\mathrm{M}_{\mathrm{w}} 7.3$ (Stress drop = 100 bars) & $106.2 \mathrm{gal}$ & $124.8 \mathrm{gal}$ \\
\hline \multicolumn{4}{c}{ Location of 1909 Taipei earthquake } \\
\hline Model 8: $\mathrm{M}_{\mathrm{w}} 6.8$ (Stress drop = 30 bars) & $22.0 \mathrm{gal}$ & $33.3 \mathrm{gal}$ \\
Model 9: $\mathrm{M}_{\mathrm{w}} 6.8$ (Stress drop = 100 bars) & $24.8 \mathrm{gal}$ & $45.7 \mathrm{gal}$ \\
Model 11: $\mathrm{M}_{\mathrm{w}} 7.3$ (Stress drop = 30 bars) & $65.7 \mathrm{gal}$ & $53.0 \mathrm{gal}$ \\
Model 12: $\mathrm{M}_{\mathrm{w}} 7.3$ (Stress drop = 100 bars) & $86.3 \mathrm{gal}$ & $100.4 \mathrm{gal}$ \\
Heterogeneous slip model: $\mathrm{M}_{\mathrm{w}} 7.3$ (Stress drop = 30 bars) & $76.1 \mathrm{gal}$ & $53.1 \mathrm{gal}$ \\
Heterogeneous slip model: $\mathrm{M}_{\mathrm{w}} 7.3$ (Stress drop = 100 bars) & $88.8 \mathrm{gal}$ & $100.6 \mathrm{gal}$ \\
\hline
\end{tabular}

(a)

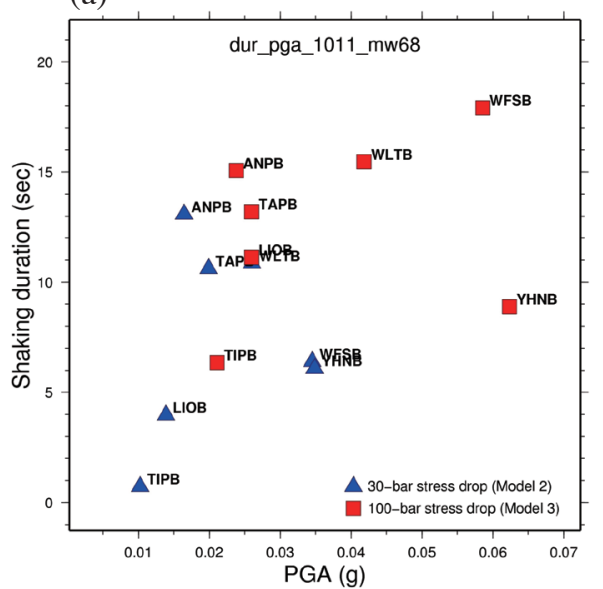

(b)

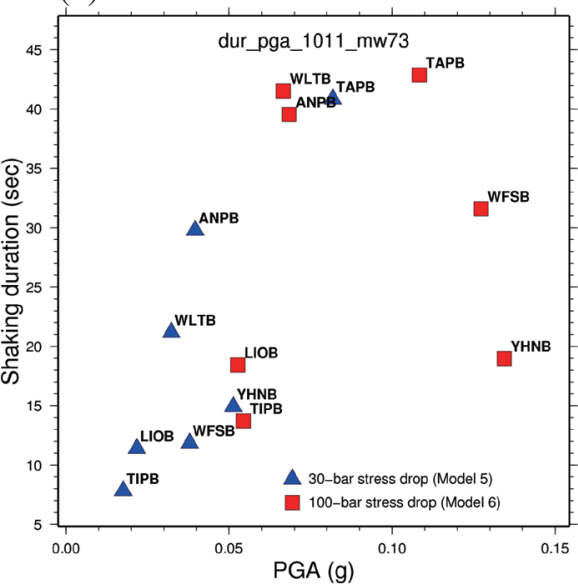

Fig. 15. PGA values and strong shaking durations from (a) Models 2 and 3, and (b) Models 5 and 6. Red squares represent PGA values and strong shaking durations from models with a 100-bar stress drop, and blue triangles represent those from models with a 30-bar stress drop. This figure shows only the comparison of the models in which the epicenter was located at the location of the small event. (Color online only) 
closest to the observed PGA values compared with the PGA values from the other models. Therefore, the 1909 Taipei earthquake was probably an earthquake with a magnitude of $M_{w} 7.3$ and stress drop of 30 bars, or equivalently a smaller magnitude of $\mathrm{M}_{\mathrm{w}} 6.8$ - 7.3 but with much higher average stress drop of more than 100 bars. Although the derived PGA values were lower than the GMPE-predicted values the simulated SA curves demonstrated high similarity with the GMPE-predicted curves. This is because in the small event high-frequency energies may decay through the structures under the Taipei basin. Therefore, earthquakes located deep within the Taipei area may cause smaller ground motions than earthquakes from outside of the Taipei area in high-frequency components, but a prolonged shaking at stations ANPB and TAPB will require further attention.

Acknowledgements We thank the Central Weather Bureau and Broadband Array in Taiwan for Seismology for offering the observed waveforms for simulation. This study was supported by the Taiwan Earthquake Research Center (TEC) funded through Ministry of Science and Technology (MOST), formerly National Science Council (NSC), with Taiwan Earthquake Model (TEM) project grant number MOST 105-2119-M-006-016. The TEC contribution number for this article is 00124 .

\section{REFERENCES}

Aki, K., 1967: Scaling law of seismic spectrum. J. Geophys. Res., 72, 1217-1231, doi: 10.1029/JZ072i004p01217. [Link]

Chen, K. C., W. G. Huang, and J. H. Wang, 2007: Relationships among magnitudes and seismic moment of earthquakes in the Taiwan region. Terr. Atmos. Ocean. Sci., 18, 951-973, doi: 10.3319/TAO.2007.18.5.951(T). [Link]

Gutenberg, B. and C. F. Richter, 1954: Seismicity of the Earth and Associated Phenomena, $2^{\text {nd }}$ edition, Princeton University Press, Princeton, $310 \mathrm{pp}$.

Irikura, K., 1986: Prediction of strong acceleration motions using empirical Green's functions. Proceeding of the Seventh Japan Earthquake Engineering Symposium, 151-156.

Kanamori, H., 1977: The energy release in great earthquakes. J. Geophys. Res., 82, 2981-2987, doi: 10.1029/ JB082i020p02981. [Link]

Kanamori, H. and D. L. Anderson, 1975: Theoretical basis of some empirical relations in seismology. Bull. Seismol. Soc. Am., 65, 1073-1095.

Kanamori, H., W. H. K. Lee, and K. F. Ma, 2012: The 1909 Taipei earthquake-implication for seismic hazard in Taipei. Geophys. J. Int., 191, 126-146, doi: 10.1111/j.1365-246X.2012.05589.x. [Link]

Komatitsch, D. and J. Tromp, 1999: Introduction to the spectral element method for three-dimensional seismic wave propagation. Geophys. J. Int., 139, 806-822, doi: 10.1046/j.1365-246x.1999.00967.x. [Link]

Komatitsch, D. and J. P. Vilotte, 1998: The spectral element method: An efficient tool to simulate the seismic response of 2D and 3D geological structures. Bull. Seismol. Soc. Am., 88, 368-392.

Kuo, C. H., K. L. Wen, H. H. Hsieh, T. M. Chang, C. M. Lin, and C. T. Chen, 2011: Evaluating empirical regression equations for $V s$ and estimating $V s 30$ in northeastern Taiwan. Soil Dyn. Earthq. Eng., 31, 431-439, doi: 10.1016/j.soildyn.2010.09.012. [Link]

Kuo, C. H., K. L. Wen, H. H. Hsieh, C. M. Lin, T. M. Chang, and K. W. Kuo, 2012: Site classification and Vs30 estimation of free-field TSMIP stations using the logging data of EGDT. Eng. Geol., 129-130, 68-75, doi: 10.1016/j.enggeo.2012.01.013. [Link]

Lee, S. J., H. W. Chen, Q. Liu, D. Komatitsch, B. S. Huang, and J. Tromp, 2008: Three-dimensional simulations of seismic-wave propagation in the Taipei basin with realistic topography based upon the spectral-element method. Bull. Seismol. Soc. Am., 98, 253-264, doi: 10.1785/0120070033. [Link]

Lee, S. J., W. T. Liang, H. W. Cheng, F. S. Tu, K. F. Ma, H. Tsuruoka, H. Kawakatsu, B. S. Huang, and C. C. Liu, 2014: Towards real-time regional earthquake simulation I: Real-time moment tensor monitoring (RMT) for regional events in Taiwan. Geophys. J. Int., 196, 432446, doi: 10.1093/gji/ggt371. [Link]

Lee, Y. T., K. F. Ma, Y. J. Wang, and K. L. Wen, 2015: An empirical equation of effective shaking duration for moderate to large earthquakes. Nat. Hazards, $\mathbf{7 5}$, 1779-1793, doi: 10.1007/s11069-014-1398-7. [Link]

Lee, Y. T., K. F. Ma, M. C. Hsieh, Y. T. Yen, and Y. S. Sun, 2016: Synthetic ground-motion simulation using a spatial stochastic model with slip self-similarity: Toward near-source ground-motion validation. Terr. Atmos. Ocean. Sci., 27, 397-405, doi: 10.3319/ TAO.2015.11.27.01(TEM). [Link]

Lin, P. S., P. S. Hsie, Y. R. Lee, C. T. Cheng, and K. S. Shao, 2012: The research of probabilistic seismic hazard analysis and geological survey of nuclear power plant: Construction of ground motion prediction equation for response spectra. Commission Report of the Institute of Nuclear Energy Research, Atomic Energy Council, Executive Yuan. (in Chinese)

Miyake, H., T. Iwata, and K. Irikura, 2003: Source characterization for broadband ground-motion simulation: Kinematic heterogeneous source model and strong motion generation area. Bull. Seismol.Soc. Am., 93, 25312545, doi: 10.1785/0120020183. [Link]

Reasenberg, P. and D. Oppenheimer, 1999: FPFIT, FPPLOT and FPPAGE, U.S. Geological Survey. Available at http://earthquake.usgs.gov/research/software/. 
Taihoku Meteorological Observatory (TMO), 1936: Report of the Severe Hsinchu-Taichung Earthquake of April 21, 1935, $160 \mathrm{pp}$.

Wang, C. Y., Y. H. Lee, M. L. Ger, and Y. L. Chen, 2004: Investigating subsurface structures and $\mathrm{P}$ - and $\mathrm{S}$-wave velocities in the Taipei basin. Terr. Atmos. Ocean. Sci., 15, 609-627.

Wu, Y. M., C. H. Chang, L. Zhao, J. B. H. Shyu, Y. G.
Chen, K. Sieh, and J. P. Avouac, 2007: Seismic tomography of Taiwan: Improved constraints from a dense network of strong motion stations. J. Geophys. Res., 112, B08312, doi: 10.1029/2007JB004983. [Link]

Yen, Y. T. and K. F. Ma, 2011: Source-scaling relationship for $M$ 4.6-8.9 earthquakes, specifically for earthquakes in the collision zone of Taiwan. Bull. Seismol. Soc. Am., 101, 464-481, doi: 10.1785/0120100046. [Link] 